\title{
Investigating the Effect of Various Fillers on Cohesive Failure Mechanism in Asphalt Mixtures
}

\author{
Gholam Hossein Hamedi*, Mohsen Sohrabi², Farhad Sakanlou², Seyed Amid Tahami \\ 1 Department of Civil Engineering, Faculty of Engineering, University of Guilan, P. O. B. 3756, Rasht, Iran \\ 2 Department of Civil Engineering, Faculty of Engineering, Urmia University, P. O. B. 165, Urmia, Iran \\ ${ }^{3}$ Department of Civil and Environmental Engineering, University of Texas at San Antonio, P. O. B. 78712, TX 78249 San Antonio, \\ United States of America \\ *Corresponding author, e-mail: hamedi@guilan.ac.ir
}

Received: 05 June 2019, Accepted: 18 November 2019, Published online: 17 January 2020

\begin{abstract}
In the current research attempts have been made to investigate the effect of various fillers on the resistance to mastic failure using mechanical and thermodynamic methods. Two types of granite and limestone aggregates with acidic and basic characteristics were used, respectively. Besides, four types of filler including calcium carbonate, hydrated lime, Portland cement and stone powder and two types asphalt binder PEN 60-70 and PEN 85-100 were used. Calcium carbonate and hydrated lime had the most effect and Portland cement and stone powder had the least effect on strength reduction. In addition, the results obtained by modified Lottman test showed that the use of hydrated lime and calcium carbonate increased resistance to moisture damage. The results of correlation coefficients show the necessity of using the effect of filler on cohesion free energy calculation in the surface free energy to investigate cohesion failure in different asphalt mixtures.
\end{abstract}

Keywords

asphalt mixtures, moisture damage, cohesion free energy, filler, pull off tensile strength, indirect tensile strength

\section{Introduction}

Roads around the world have been widely paved using asphalt concrete mixtures. Increasing axle loads, traffic volume, construction and design errors cause major damages in asphalt pavement including rutting, fatigue, moisture damage and low temperature cracking that reduce the performance of pavements $[1,2]$. Moisture damage is defined as the reduction of strength and durability of asphalt in the presence of water [3]. The mechanisms of reduction in asphalt mixtures characteristics lead to moisture damage in two main stages:

First stage: Diffusion process (the moisture makes its way into the asphalt mixture as vapor or liquid)

Second stage: Response of the system (the loss of load bearing capacity in materials constituting the mixture) [4-6].

The most important mechanisms which occur in the second stage (response of the system) include:

Detachment: Separation of an asphalt film from an aggregate surface by a thin film of water without an obvious break in the binder layer;
Displacement: Loss of material from the aggregate surface through a break in the asphalt film and/or possible separation of the aggregate/mastic interface;

Dispersion: Weakening of the cohesion in the asphalt binder or mastic due to long-term diffusion periods and loss of material due to the presence of flow;

Desorption: washing away of the outer layers of mastics due to the presence of flow;

Spontaneous emulsification: Inverted emulsion of water droplets in binders [7-9].

Considering the above mentioned mechanisms, it is observed that in the second stage (response of the system), mastic cohesion strength and/or the aggregate-binder adhesion reduces. Therefore, some of the mentioned mechanisms such as spontaneous emulsification and dispersion mechanism can affect mastic cohesion and therefore, moisture sensitivity through chemical and thermodynamic together with chemical processes, respectively, which lead to cohesion failure $[4,10,11]$. 
Moisture damage is a complicated phenomenon. The chemical and physical properties of asphalt mixtures including the chemical compounds of mastic and the aggregate, surface properties, mineralogy and qualitative and combined properties of filler affect the speed of its occurrence [12]. Despite the mentioned importance of the impact of materials used in the asphalt mixtures on the adhesion failure mechanism, previous researches did not pay much attention to the influence of mastic types on the effective factors in the occurrence of cohesion failure. In the thermodynamic studies, the Surface Free Energy (SFE) components of asphalt binder are used to calculate the cohesion free energy of asphalt binder, adhesion free energy of asphalt binder-aggregate and debonding energy of asphalt binder-aggregate [13]. However, failure occurs in mastic, not in asphalt binder. Also, in failure of adhesion and debonding, attention should be paid to the components of the SFE of mastic. However, in the relationships provided according to previous studies, the components of SFE of asphalt binder are used. Accordingly, this research tried to investigate the effect of different fillers on cohesion free energy in two different conditions; a) considering the components of SFE of asphalt binder and b) considering the components of SFE of mastic.

Research studies conducted by Kanitpong and Bahia [14] on measuring cohesion strength using dynamic shear rheometer show that tensile strength of asphalt mixture is closely related to cohesion. In addition, the presence of moisture in cracks and empty connected spaces in asphalt mixture under traffic loading leads to the fast water flow into the mix and the continued flow of water in the mastic can have erosion effect on mastic and causes mastic particles to be detached from each other. In this process, mastic cohesion plays a significant role in this type of moisture damage [8]. Therefore, changes of mastic cohesion strength can affect the better control and performance of asphalt mixtures against moisture damage. Tan and Guo [15] investigated the SFE of asphalt binder using sessile drop method, and the SFE of fillers was measured using column wicking method. The results of their study show that the control asphalt binder has higher cohesion free than the modified asphalt. Alvarez et al. [16] focused on the analysis of the filler effect on asphalt-aggregate interfaces of HMA based on thermodynamic properties (i.e., measurements of SFE, SFE, performed on asphalts, mastics (asphalt-filler combinations), and aggregates).

One of the methods to change mastic cohesion strength is changing the consumed filler. Faheem and Bahia [17] approved that the type of the filler's minerals and its concentration can affect stiffness of the mastic. Additionally, the filler-binder interface has an important effect on rheological properties and stiffness of the mastic. This interface is different in various types of fillers and binders [18]. In another research in which the effect of filler properties (the amount of roundness, length to diameter ratio and etc.,) on cohesion strength of asphalt mixtures was evaluated, it was found that these properties have a significant effect on cohesion strength (at low temperature) [19]. Moreover, research on filler made by treated fly ash with Silane coupling agent (compound fly ash modifier) show that using this filler causes an increase in indirect tensile strength (ITS) and an increase in load bearing capacity. It has also a positive effect on creep and increases fatigue life in asphalt mixtures [20]. Accordingly, the conducted research studies indicate the undeniable effect of filler on asphalt mixtures properties.

In the majority of cases, the mechanical tests have been used in such research studies to investigate properties of asphalt mixture. In spite of the simple and useful results obtained by mechanical tests, these methods do not focus on measuring the main properties of materials related to moisture damage and the represented indictor shows the resistance of asphalt mixture to several different damage mechanisms [21]. As cohesion and adhesive strength of asphalt mixtures is based on thermodynamic concepts related to SFE properties of materials (filler, binder and aggregate), therefore, the characterization of these concepts can be a great help with selecting materials resistant to moisture sensitivity and can investigate the role of different components of asphalt mixture [22].

Since the experimental design includes assessment of work of cohesion, based on SFE, (i.e., cohesion free energy) a more comprehensive state of the art needs to be documented on the analysis of mastics based on SFE.

The most important desired goals and objectives of the current research include:

Investigating the amount of changes occurred in cohesion free energy parameter as a result of adding fillers to binder, and comparing this parameter in two states of base binder (without filler) and mastic (with filler);

Investigating the effect of filler type on moisture sensitivity of asphalt mixtures through laboratory tensile strength tests (Pull Off method);

Investigating the effect of filler type on moisture sensitivity of asphalt mixtures using laboratory modified Lottman test; 
Determining the correlation between cohesion strength of asphalt mixtures and moisture sensitivity tests in two different states. In the first state by considering mastic SFE (binder and filler) and in the second state by considering SFE of binder, and finally, comparing these two states.

\section{SFE method}

As adhesive and cohesion failures in moisture damage of asphalt mixtures are directly related to surface properties of the utilized materials, SFE method can provide an appropriate way to select materials resistant to moisture sensitivity [22]. The work of adhesion and surface energies play a vital role in adhesion and in understanding theories of adhesion [23].

SFE is defined as the amount of work done to create a unit area of new surface of the material in a vacuum [24]. SFE of a single-phase material is expressed based on polar and non-polar components of that material SFE as follow [25]:

$\gamma^{\text {Total }}=\gamma^{\text {Dispersive }}+\gamma^{\text {specific }}$.

Where, $\gamma^{\text {Total }}$ is total SFE of a single phase material, $\gamma^{\text {Dispersive }}$ shows dispersive forces (Lifshitz-Van der Waals forces) and $\gamma^{\text {specific }}$ shows forces related to specific interactions.

As SFE of materials is consisted of three separate components based on the origin of the intermolecular forces, it can be written according to acid-base components as follows [26]:

$\gamma_{i}=\gamma_{i}^{l w}+\gamma_{i}^{A B}$.

Where $\gamma_{i}$ is total SFE, $\gamma_{i}^{l w}$ is Lifshitz-Van der Waals components of SFE and $\gamma_{i}^{A B}$ is polar component of SFE.

$\gamma_{i}^{A B}=2 \sqrt{\gamma^{+} \gamma^{-}}$

Where, $\gamma_{i}^{+}$and $\gamma_{i}^{-}$are acidic and basic components of SFE respectively.

$\gamma^{\text {Total }}=\gamma^{L W}+2 \sqrt{\gamma^{+} \gamma^{-}}$

The parameters of Eq. (4) are previously defined.

The relationship between Gibbs free energy (G), surface energy $(\gamma)$ and work of cohesion $\left(W^{c}\right)$ is obtained based on Eq. (5).

$W_{i}^{c}=-\Delta G_{i}^{c}=\gamma_{i}$

Where, $W_{i}^{c}$ is work of cohesion, $\Delta G_{i}^{c}$ is Gibbs energy of cohesion and, $\gamma_{i}$ is total SFE.
In order to better understand this issue, the equation between work of cohesion and SFE of a bulk material is presented in Fig. 1.

\section{Laboratory program}

In order to attain the intended research goals, the laboratory program was implemented based on the Fig. 2 In addition, in order to increase the accuracy of laboratory data, each sample was tested with three replicates.

\subsection{Materials}

In order to prepare specimens with different compounds, limestone and granite aggregates with middle gradation, based on ASTM D3515-01 standard [28], were used in the current research. Two types of aggregates were selected to evaluate the effects of acidic and basic properties on moisture damage performance. In addition, two types of 60-70 and 85-100 penetration grade binders were used. The optimum binder content was obtained $6 \%$ and $5.5 \%$ for limestone and granite aggregates based on Marshall mix design test, respectively. The results of the preliminary tests show that the use of 3.5 to $5 \%$ of the additives used in this study had the best performance in reducing the moisture damage of asphalt mixtures. Due to the comparative analysis between control and modified asphalt binders, in this study, $4 \%$ filler was used in all samples. $4 \%$ filler content for each filler type including stone powder, calcium carbonate, hydrated lime, and Portland cement were used in this research. Stone powders are powder of granite and limestone aggregates that used in this study. The details of mixtures with different compounds are presented in the following Table 1.

\subsection{Moisture sensitivity tests}

\subsubsection{Mechanical tests}

\section{Pull Off test}

The results of research conducted by Copeland et al. [29] show that Pull Off test is an acceptable method to measure cohesion strength for determining durability against

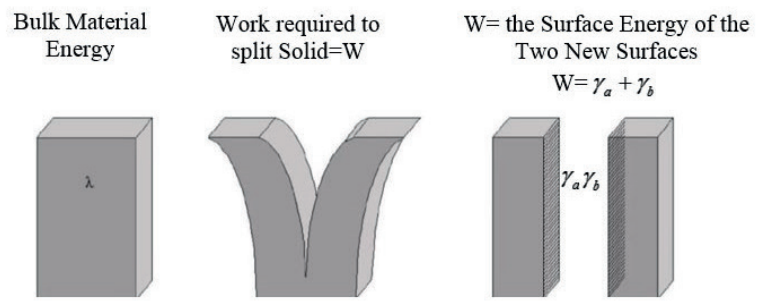

Fig. 1 Thermodynamic cohesion process [27] 


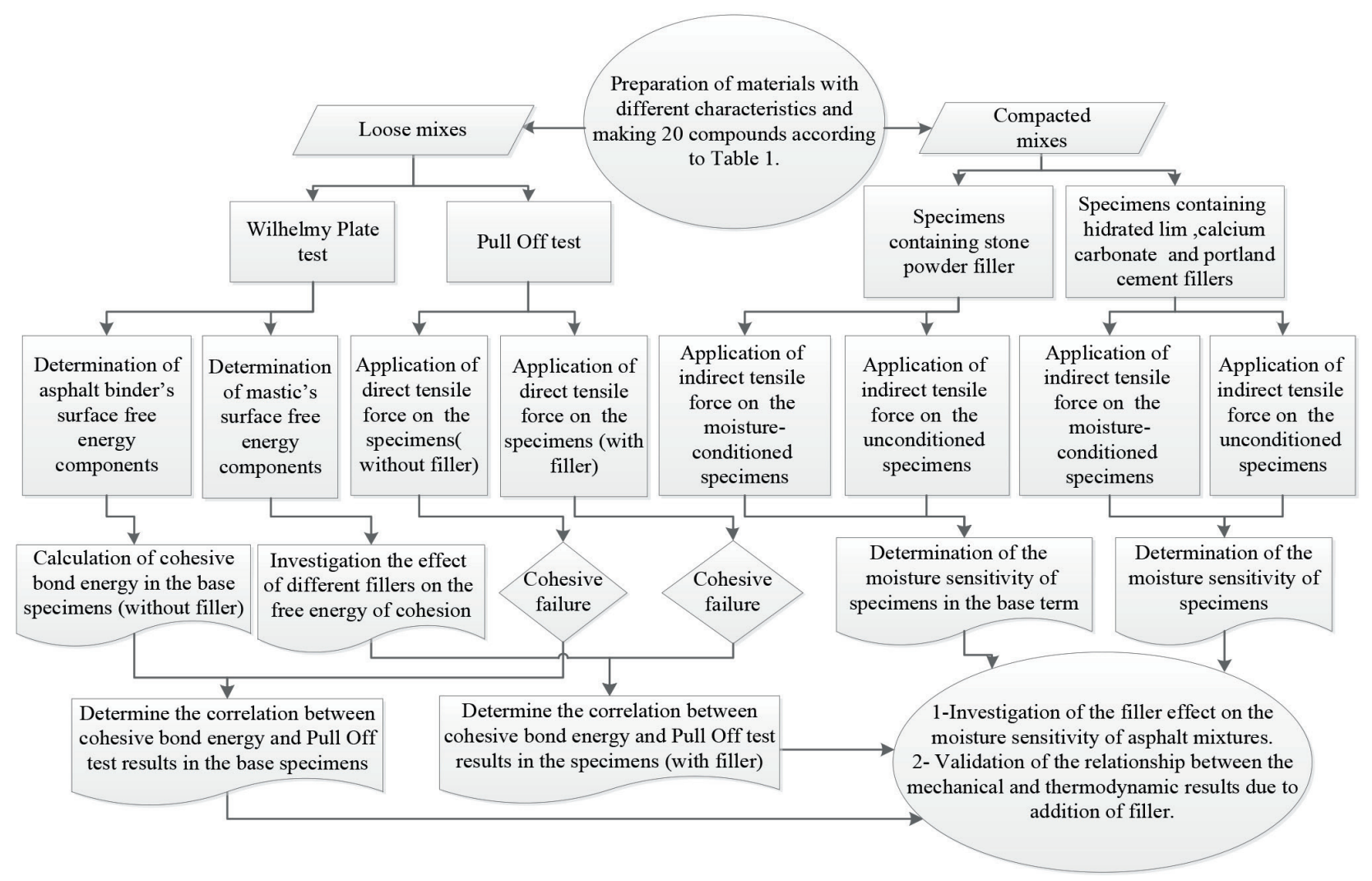

Fig. 2 .Laboratory program flowchart

Table 1 Materials properties used in this study

\begin{tabular}{|c|c|c|}
\hline Mixture & Aggregate & Mastic \\
\hline 1 & & AC $60-70$ without additives \\
\hline 2 & & AC $60-70$ with stone powder \\
\hline 3 & & AC $60-70$ with hydrated lime \\
\hline 4 & & AC $60-70$ with calcium carbonate \\
\hline 5 & Limestone & AC 60-70 with Portland cement \\
\hline 6 & & AC $85-100$ without additives \\
\hline 7 & & AC $85-100$ with stone powder \\
\hline 8 & & AC $85-100$ with hydrated lime \\
\hline 9 & & AC $85-100$ with calcium carbonate \\
\hline 10 & & AC $85-100$ with Portland cement \\
\hline 11 & & AC $60-70$ without additives \\
\hline 12 & & AC $60-70$ with stone powder \\
\hline 13 & & AC $60-70$ with hydrated lime \\
\hline 14 & & AC $60-70$ with calcium carbonate \\
\hline 15 & Granite & AC 60-70 with Portland cement \\
\hline 16 & & AC $85-100$ without additives \\
\hline 17 & & AC $85-100$ with stone powder \\
\hline 18 & & AC $85-100$ with hydrated lime \\
\hline 19 & & AC $85-100$ with calcium carbonate \\
\hline 20 & & AC $85-100$ with Portland cement \\
\hline
\end{tabular}

moisture. This test measures coupling and tensile strength of binder adhered to a steel plate. The basis for this test is that the pressure required for detaching conditioned specimens is obtained at $25^{\circ} \mathrm{C}$ using pneumatic adhesion test. The tensile rate in this test is about $66 \mathrm{kPa} / \mathrm{s}$. With considering the conducted research on Pull Off test by researchers, it was observed that the failure type in this test varies from cohesion failure under dry conditions to adhesive or mixed failure under wet conditions. In addition, when the thickness of asphalt binder film on the aggregate surface is high, there is cohesion failure and when the thickness of the asphalt binder film is low, there is adhesive failure [30, 31]. Accordingly, Fig. 3 represents the mastic under test in this research, which has been conducted with different types of fillers on the aggregate surface. During the test, asphalt binder samples were considered under wet conditions and the thickness of the asphalt binder film was selected in a way that failure occurs in the asphalt binder film. Four moisture conditioning, the asphalt binder samples are kept in the freezer at $-18{ }^{\circ} \mathrm{C}$ for 16 hours. Then, the specimens are transferred to water bath at temperature of $60{ }^{\circ} \mathrm{C}$ for 24 hours. Then, the specimens are kept at room temperature $\left(25^{\circ} \mathrm{C}\right)$ for 24 hours. 


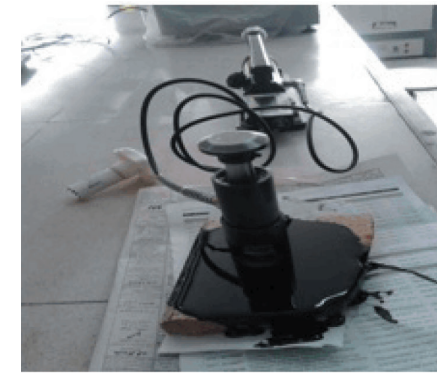

(a)

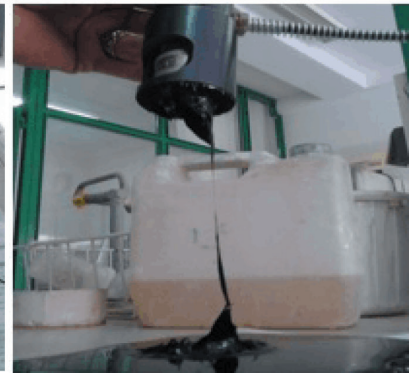

(b)

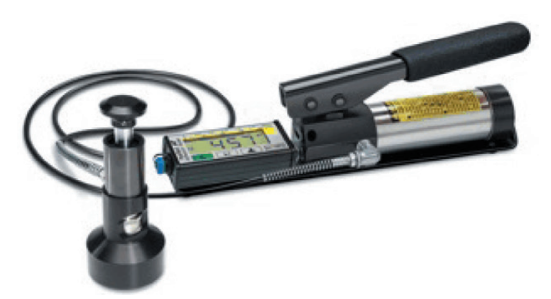

(c)

Fig. 3 Pull Off tensile strength test

\section{Modified Lottman test (AASHTO T283)}

The modified Lottman test is used to determine the moisture sensitivity of asphalt mixtures. In this test, first 6 specimens $(62.5 \times 100 \mathrm{~mm})$ were prepared with $7 \pm 0.5 \%$ air void. Then, half of these specimens were being under moisture conditioning in order to determine the potential of resistance to moisture. Finally, the ratio of ITS of conditioned specimens to dry specimens under loading with a rate of $2 \mathrm{in} / \mathrm{min}$ at $25^{\circ} \mathrm{C}$ is presented as an indicator to evaluate moisture sensitivity.

To apply moisture conditioning, the intended specimens are saturated by creating partial vacuum for 5 minutes. Then the mass of specimens is measured and their saturation percentage is obtained to be 70-80\% using Eq. (6). After this stage, the saturated specimens are kept in the freezer at $-18{ }^{\circ} \mathrm{C}$ for 16 hours. Then the specimens are transferred to water bath at temperature of $60{ }^{\circ} \mathrm{C}$ for 24 hours, and at the last stage the specimens are kept at room temperature $\left(25^{\circ} \mathrm{C}\right)$ for 24 hours.

Saturation percentage of specimens is obtained by Eq. (6):

$$
s^{\prime}=\frac{100\left(W_{S S D}-W_{D}\right)}{\frac{P_{a} E}{100}} .
$$

Where, $s^{\prime}$ is saturation percentage, $W_{S S D}$ is mass of the saturated surface dry sample after vacuum saturation, $W_{D}$ is mass of the dry sample, $P_{a}$ is the percentage of air voids, and $E$ is the specimens volume.

The indirect tensile value at the time of specimens' failure is obtained by Eq. (7):
$I T S=\frac{2000 F}{t \pi d}$

Where, ITS is indirect tensile strength of the specimens $(\mathrm{kPa}), \mathrm{F}$ is the amount of failure moment force $(\mathrm{N}), \mathrm{t}$ is the thickness of the asphalt specimen ( $\mathrm{mm})$, and $\mathrm{d}$ is diameter of the asphalt specimen ( $\mathrm{mm})$.

After obtaining tensile strength of specimens under wet and dry conditions, the final result for moisture sensitivity or stripping potential is obtained by dividing the mean of the ITS of wet samples to that of dry ones as follows:

$T S R=\left(\frac{I T S_{w e t}}{I T S_{d r y}}\right) \times 100$.

Where, TSR is the ratio of indirect tensile strength, $I T S_{\text {wet }}$ is the mean of ITS of wet specimens $(\mathrm{kPa})$ and $I T S_{d r y}$ is the mean of ITS of dry specimens $(\mathrm{kPa})$ [32].

If the obtained value for TSR is less than 80, the mixture is considered as moisture susceptible [33].

\section{Thermodynamic tests}

There are several methods to obtain thermodynamic parameters of materials. In the current research the SFE parameters of binder and mastic were obtained using Wilhelmy Plate (WP) method that developed by Bhasin [34] and Hefer et al. [35]. Before explaining WP technique, equations of this test are presented in the following:

Considering Young-Dupree equation, when a drop of liquid is placed on a solid object the following equation exists:

$\gamma_{S V}=\gamma_{S L}+\gamma_{L V} \cos \theta$

Where, $\gamma_{S V}$ and $\gamma_{L V}$ are the surface free energies of ' $S$ ' and ' $L$ ' when they are separated in a vapor medium ' $V$ ', $\gamma_{S L}$ is the interfacial energy between these materials and $\theta$ is contact angle of a probe liquid, $L$, in contact with a solid, $S$.

On the other hand, the following equation exists between two materials' work of adhesion:

$W_{S L}=\gamma_{S}+\gamma_{L}-\gamma_{S L}$.

Where, $W_{S L}$ is work of adhesion between $L$ and $S, \gamma_{S}$ and $\gamma_{L}$ are SFE of $S$ or $L$, and $\gamma_{S L}$ is interfacial energy between the two materials in contact.

$W_{S L}=2\left[\sqrt{\gamma_{S}^{L W} \gamma_{L}^{L W}}+\sqrt{\gamma_{S}^{+} \gamma_{L}^{-}}+\sqrt{\gamma_{S}^{-} \gamma_{L}^{+}}\right]$

Where, $\gamma^{L W}$ is the nonpolar component, $\gamma^{+}$is the Lewis acid component and $\gamma^{-}$is the Lewis base component. In this equation, the solid represented by suffix ' $S$ ' is the asphalt binder under consideration and the liquid represented by suffix ' $L$ ' is any probe liquid. 
By integrating Eqs. (9) and (10), Eq. (12) is obtained:

$W_{S L}=\gamma_{L}(1+\cos \theta)$.

Where, $\gamma_{L}$ is SFE of material $L$.

Finally, considering the obtained formula, the adhesive free energy can be written based on the SFE components as follows:

$\gamma_{L}(1+\operatorname{CoS} \theta)=2\left[\sqrt{\gamma_{S}^{L W} \gamma_{L}^{L W}}+\sqrt{\gamma_{S}^{+} \gamma_{L}^{-}}+\sqrt{\gamma_{S}^{-} \gamma_{L}^{+}}\right]$.

Where, $\gamma^{+}$is, $\gamma^{-}$is and $\gamma^{L W}$ are acidic, basic and non-polar components of SFE, respectively.

\section{WP method}

In this test, a thin glass is coated by binder uniformly, and then it is immerged in a specific solution. After that, it is withdrawn from the container at a slow and constant speed. At the same time, the contact angle between binder and liquid is measured. This process is shown in the Fig. 4. As illustrated, two types of contact angles are formed during withdrawal and immersion of the plate into the solution. Finally, the amount of $\theta$ in Eq. (13) is obtained using WP method [36].

As mentioned before, this technique is based on kinetic forces equilibrium, therefore, $\theta$ is obtained using this method according to the following stages:

When a plate is suspended in the air, the following equilibrium equation is used to determine the amount of required force to keep it in equilibrium state.

$$
F=W_{\text {Plate }}+W_{\text {asphalt }}-V \cdot \rho_{\text {air }} \cdot g
$$

Where, $F$ is the required force to keep the plate stable, $W_{\text {Plate }}$ is the weight of plate, $W_{\text {asphalt }}$ is the weight of asphalt binder, $V$ is the binder plate volume, $g$ is the local acceleration of gravity, and $\rho_{\text {air }}$ is the specific weight of the air.

The following equation is used when the plate soaked in the binder is immerged in the liquid:

$$
\begin{aligned}
& F=W_{\text {Plate }}+W_{\text {asphalt }}-V \cdot \rho_{\text {air }} \cdot g \\
& -\left(V-V_{\text {im }}\right) \cdot \rho_{\text {air }} \cdot g+P_{t} \cdot \rho_{L} \cdot g \cdot \cos \theta
\end{aligned}
$$

Where, $P_{t}$ is the perimeter of plate soaked in binder, $\rho_{L}$ is the total SFE of liquid, $\theta$ is the dynamic contact angle between binder and test liquid, $V_{i m}$ is the volume of the immerged part of the plate soaked in binder, $V$ is the total volume of the binder plate, and $\rho_{L}$ and $\rho_{\text {air }}$ are the specific weight of the test liquid and air, respectively. The parameters of Eq. (15) are previously introduced.

By subtracting the Eqs. (14) and (15) from each other Eq. (16) can be obtained:

$\Delta F=P_{t} \rho_{L} g \cos \theta-V_{i m} \cdot \rho_{L} \cdot g+V_{i m} \cdot \rho_{\text {air }} \cdot g$.

Where, $\Delta F$ is difference forces in the air and the water, and other parameters are previously defined.

Finally, by writing the above equation in terms of $\theta$ Eq. (17) is obtained:

$\cos \theta=\frac{\Delta F+V_{i m} \cdot g \cdot\left(\rho_{L}-\rho_{\text {air }}\right)}{P_{t} \gamma_{L}}$.

The parameters of Eq. (17) are previously defined.

Therefore, by measuring the contact angle between the plate coated with binder and at least three different research liquids, 3 different angels are obtained. Finally, by substituting $\theta$ in Eq. (13) and forming the system of linear Eq. (18), SFE components are obtained. Then, the total SFE in Eq. (4) is calculated using the obtained components. It is worth mentioning that usually three liquids including water, formamide and glycerol are used in this test. The thermodynamic parameters of these liquids are presented in Table 2.

$$
\begin{aligned}
& {\left[\begin{array}{lll}
A_{11} & A_{12} & A_{13} \\
A_{21} & A_{22} & A_{23} \\
A_{31} & A_{32} & A_{33}
\end{array}\right]\left[\begin{array}{l}
X_{1} \\
X_{2} \\
X_{3}
\end{array}\right]=\left[\begin{array}{l}
Y_{1} \\
Y_{2} \\
Y_{3}
\end{array}\right]} \\
& A_{1 i}=\frac{2 \sqrt{\gamma_{L i}^{L W}}}{\gamma_{L i}} \quad A_{2 i}=\frac{2 \sqrt{\gamma_{L i}^{+}}}{\gamma_{L i}} \quad A_{3 i}=\frac{2 \sqrt{\gamma_{L i}^{-}}}{\gamma_{L i}} \\
& X_{1}=\sqrt{\gamma_{S}^{L W}} \quad X_{2}=\sqrt{\gamma_{S}^{-}} \quad X_{3}=\sqrt{\gamma_{S}^{+}} \\
& Y_{i}=1+\cos \theta_{i}
\end{aligned}
$$
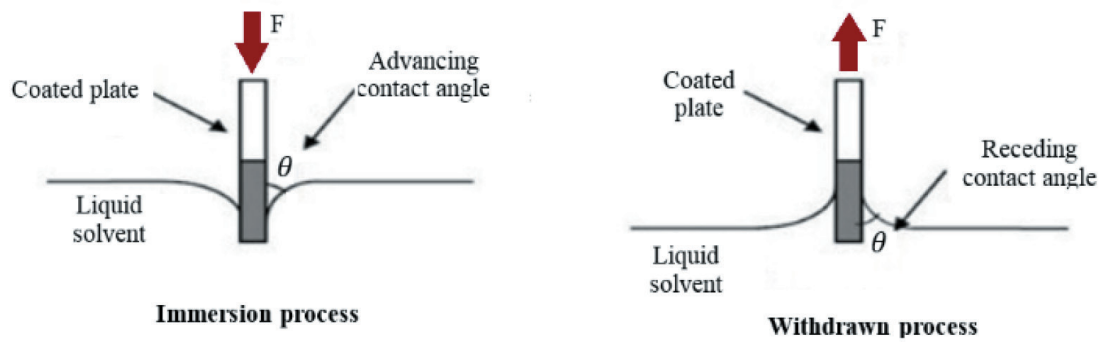

Fig. 4 WP dynamic method for advancing and receding contact angles 
Table 2 Surface energy properties of the solvents $\left(\mathrm{ergs} / \mathrm{cm}^{2}\right)$

\begin{tabular}{lccccc}
\hline Solvents & \multicolumn{5}{c}{ Solvents } \\
& $\gamma_{t}$ & $\gamma_{A B}$ & $\gamma_{B}$ & $\gamma_{A}$ & $\gamma_{L W}$ \\
\hline Water & 72.8 & 51.0 & 25.5 & 25.5 & 21.8 \\
Glycerol & 64.0 & 30.0 & 57.4 & 3.92 & 34.0 \\
Formamide & 58.0 & 19.0 & 39.6 & 2.28 & 39.0 \\
\hline
\end{tabular}

\section{Results and discussion}

\subsection{Direct tensile strength with Pull Off test}

By investigating the presented results in Figs. 5 and 6, it can be concluded that although in the previous researches often adhesive failure occurred by considering conditioning process on binder, in the current research the failure occurred in the form of cohesion mechanism even after conditioning of binder. Also, the same behavior could be observed in both types of granite and limestone aggregates with different mastics against tensile force, indicating this issue. Therefore, filler properties have a significant effect on resistance against tensile force, and

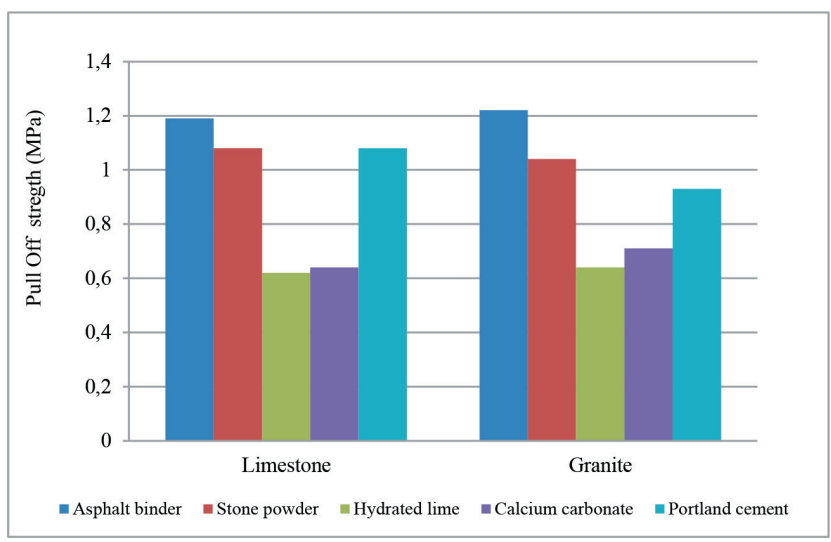

Fig. 5 Tensile strength values on the control asphalt binder and different mastics (AC 60-70)

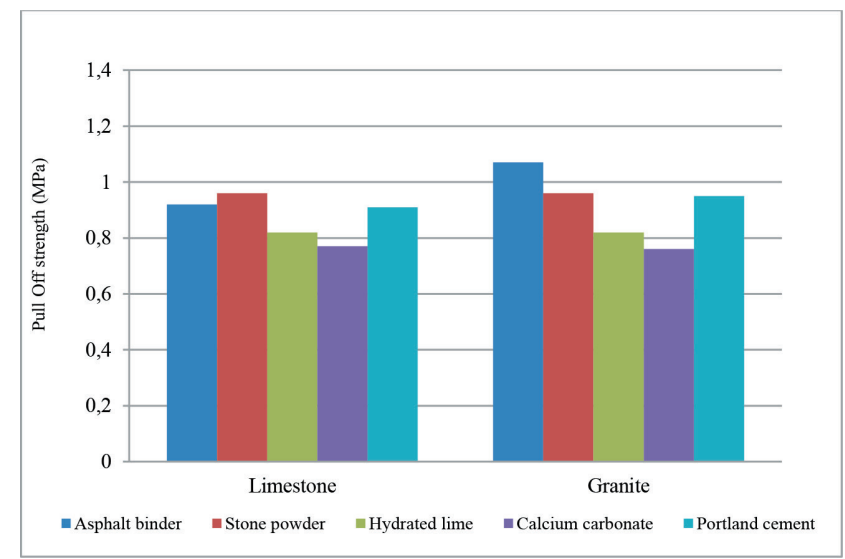

Fig. 6 Tensile strength values on the control asphalt binder and different mastics (AC 85-100) generally, adding filler to binder causes a reduction in mastic cohesion strength. In addition, by relative comparison of different fillers, it is observed that stone powder and Portland cement fillers had a less effect on reducing cohesion strength, but calcium carbonate and hydrated lime showed the most effect and the least resistance against tensile force, respectively. Finally, in more exact investigation it is observed that the minimum value of Pull Off is related to the hydrated lime filler in asphalt binder $60-70$ by $48 \%$ reduction in cohesion strength, while the minimum value of this parameter was assigned to calcium carbonate filler by $29 \%$ reduction in cohesion strength in asphalt binder 85-100. According to the results, it can be seen that the role of filler in reducing cohesion strength is more sensible in asphalt binder 60-70.

\subsection{ITS test}

The ITS test results in dry and wet conditions for different samples with two different types of asphalt binders are provided in Figs. 7 and 8.

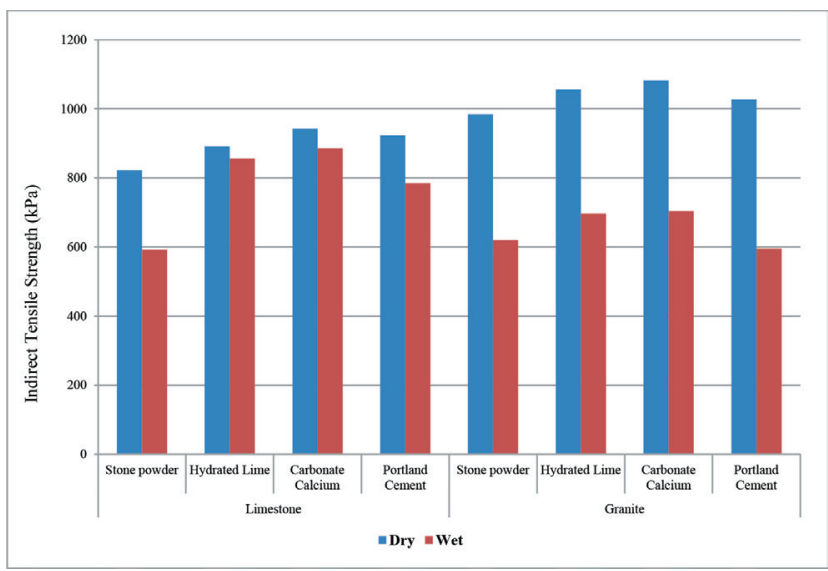

Fig. 7 ITS values for 85-100 pen binder (AC 85-100)

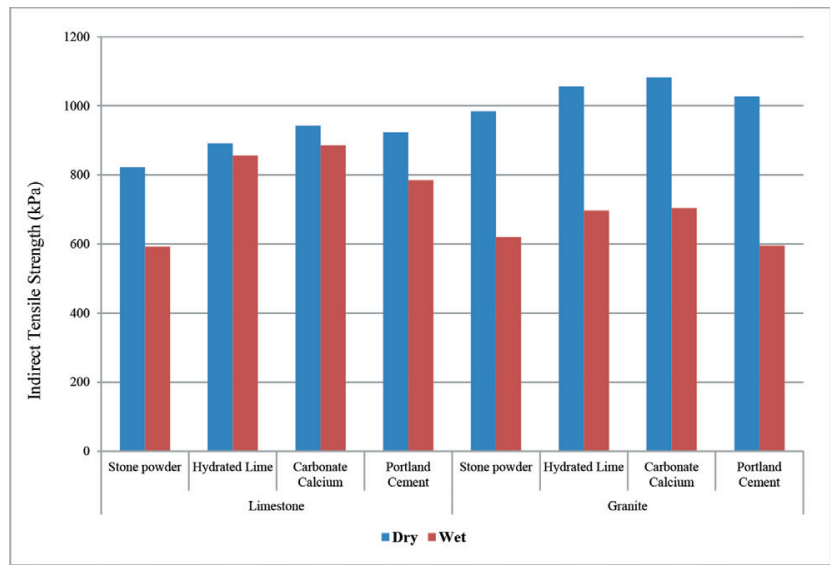

Fig. 8 ITS values for 60-70 pen binder (AC 60-70) 
According to the data of Fig. 7, it is clear that the use of different fillers (hydrated lime, calcium carbonate and Portland cement) increases the ITS of the samples in samples made with 60-70 asphalt binder for both types of limestone and granite aggregates in dry conditions. Meanwhile, hydrated lime filler has the greatest effect on the increase of ITS in both types of limestone and granite samples. Finally, it can be observed that the ITS in granite aggregates is more than limestone aggregate. ITS of granite aggregates in wet condition has been severely reduced due to the high hydrophilicity of minerals in granite aggregates compared to limestone aggregates. In other words, due to the aggregate-forming minerals, the high percentage of $\mathrm{SiO}_{2}$ minerals in granite aggregates increases their hydrophilicity in the presence of water, and finally, asphalt binder is easily separated from the surface of aggregates; Therefore, strong bonds in granite aggregate with dry conditions are lost in the presence of moisture, and a great decline in the strength of the group is created, while limestone aggregates have a better strength to wet conditions due to their hydrophilic properties.

It can be seen from the data of Fig. 8 that the increase of ITS in dry conditions is also due to the use of different fillers in samples made with 85-100 asphalt binder. In relation to this type of asphalt binder, calcium carbonate filler has the greatest effect on the increase of ITS in both samples made of limestone and granite. Also, similar to the previous, the ITS of granite aggregates is greater than that of limestone aggregate. The use of hydrated lime and calcium carbonate fillers increases strength to wet conditions and the effect of improving the strength with the two filler types mentioned is more remarkable in limestone aggregate. Also, the percentage increase in strength in this state is higher than the increase in strength in dry state. Finally, it is observed that the use of Portland cement filler has a negative effect on ITS in wet conditions in limestone and granite aggregates. It can be seen that the use of different fillers increases the ITS in samples made with 85-100 asphalt binder, and unlike 60-70 asphalt binder that use of Portland cement filler does not have an effect on ITS, the increase of strength to limestone aggregate with Portland cement filler has been observed in 85-100 asphalt binder. Also, the use of calcium carbonate has the greatest effect on samples made with 85-100 asphalt binder. This is while the highest strength is obtained in 60-70 asphalt binder using hydrated lime.

Considering the presented results in Figs. 9 and 10, it is observed that hydrated lime and calcium carbonate fillers has caused an increase in the resistance to moisture

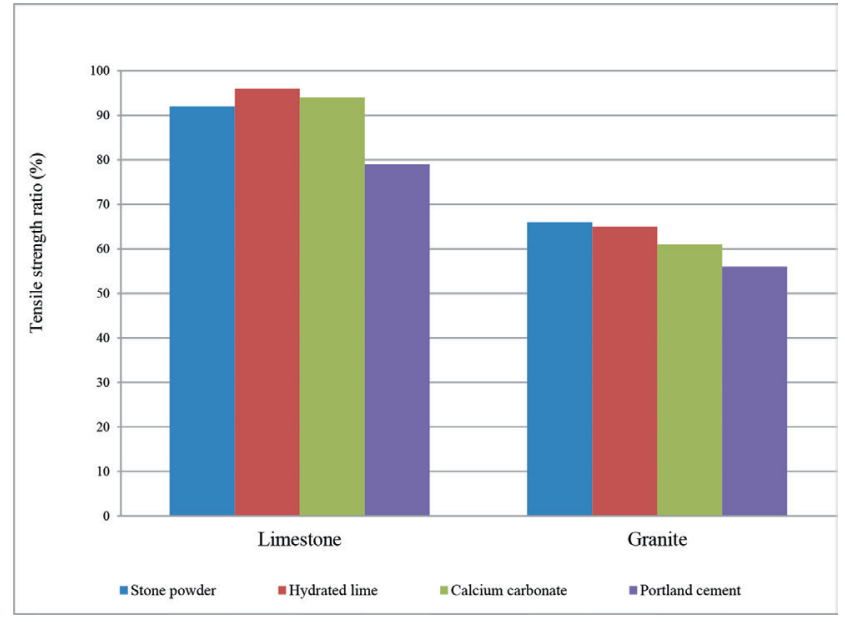

Fig. 9 TSR values for 60-70 pen binder (AC 60-70)

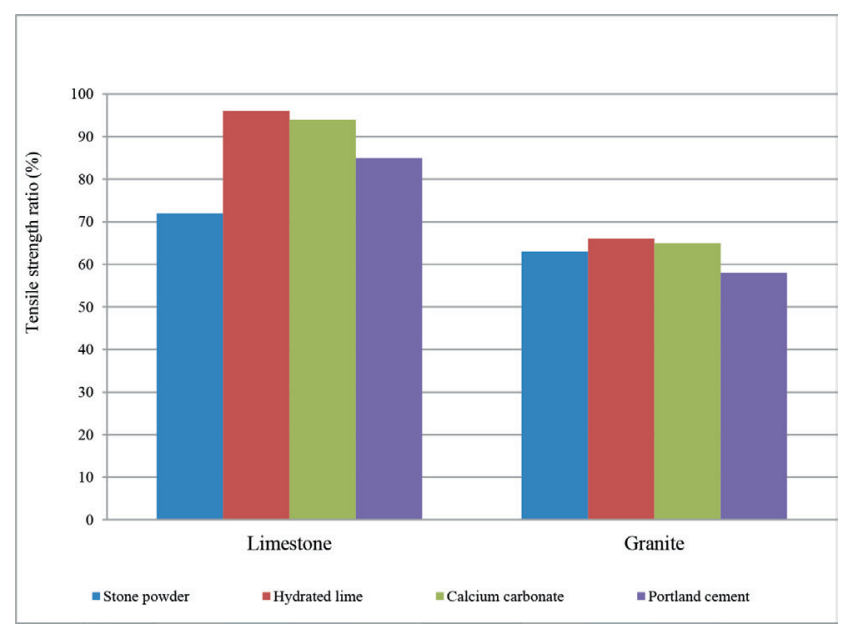

Fig. 10 TSR values for 85-100 pen binder (AC 85-100)

sensitivity. Of course, this does not hold true with regard to mixtures containing granite aggregate together with asphalt binder 60-70, and in this case the mixture containing stone powder filler has the maximum value. However, in contrast to the above mentioned fillers, mixtures containing Portland cement show a different behavior, and this filler has shown a suitable resistance to moisture only in mixtures containing limestone and asphalt binder 85-100 by $18 \%$ increase in TSR. Of course, other fillers in this group has also a significant increase in TSR value compared to the base state, in a way that, in comparison to the base state, hydrated lime and calcium carbonate fillers have the maximum increase by $33 \%$ and $30 \%$, respectively; and using filler in this group has been more effective. In addition, it is observed that compounds composed of limestone aggregate with both types of binder have almost the same behavior with hydrated lime and calcium carbonate fillers, and the numerical value of TSR in both types of binder is $96 \%$ and $94 \%$, respectively. 
As the types of minerals constituting aggregate have a significant effect on moisture sensitivity, in the presented results it is observed that granite aggregates show less strength. This is due to the high percentage of silicon dioxide $\mathrm{SiO}_{2}$ minerals which increase water absorption of granite aggregate. In contrast, limestone aggregates have a high percentage of calcium oxide $\mathrm{CaO}$ mineral which increases water desorption of aggregate.

\subsection{Cohesion free energy of binder}

Results of measuring cohesion free energy components of binder and mastic used in the current research are shown in Fig. 11. As shown, generally, adding filler to binder causes a reduction in cohesion free energy (except in mixtures containing stone powder together with asphalt binder $60-70$ ) and this reduction rate in asphalt binder $60-70$ is more than asphalt binder $85-100$. Of course, this issue holds also true with regard to the results of Pull Off test. In comparison of mastics, the maximum reduction rate of cohesion free energy to the base state in asphalt binder $60-70$ is related to the hydrated lime filler by about $42 \%$. However, for asphalt binder 85-100, calcium carbonate filler has the maximum reduction in cohesion free energy by about $28 \%$. Also in this case, the reduction of strength rate is almost equal to the reduction of strength rate in Pull Off test. In addition, it is observed that in asphalt binder $60-70$, mastic containing stone powder filler has the maximum amount of cohesion free energy by $3 \%$ increase to base binder. Whereas in specimens made by asphalt binder $85-100$, mastic containing Portland cement filler by $1.5 \%$ reduction to the base state has the maximum amount of cohesion free energy amongst mastics.

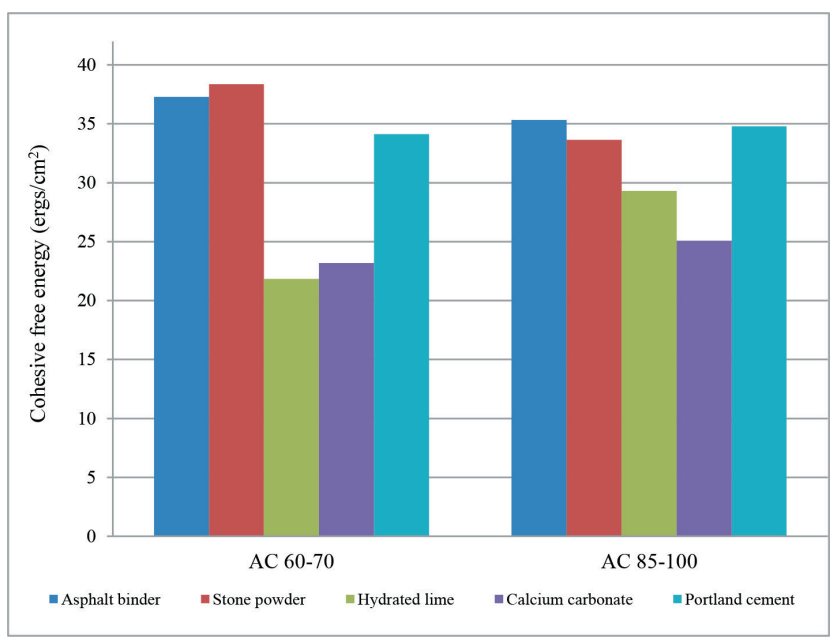

Fig. 11 Values of asphalt binder and different mastics cohesion free energy
The cohesion free energy of the asphalt binder is strongly related to the cracking characteristics of asphalt mastics and mixtures. The cohesion properties of the binder and mastic determine the fracture resistance of asphalt mixtures [37]. Cohesion is considered to be a parameter with a dual effect; its increase leads to improvement of resistance to moisture damage of cohesion type in the one hand and is considered to be a positive effect, and reduces the wettability of binder on aggregate surface and is considered to be a negative effect on the other hand. The higher and more positive the value of spreading, is the greater the work of adhesion would be compared to the cohesion energy of the adhesion. A negative value of spreading represents a finite contact angle and zero corresponds to final equilibrium (Eq. (19)).

spreding $=W^{\text {adhesion }}-W^{\text {cohesion }}$

For this reason, increasing cohesion free energy cannot be a sufficient reason to improve moisture sensitivity of asphalt mixture. Therefore, results of cohesion free energy cannot be compared with modified Lottman test results. The comparison between direct tensile test results with the results of cohesion free energy obtained by WP method is presented in Fig. 12. A significant relationship is observed between the results of two tests. By increasing the cohesion free energy of mastic or binder, tensile strength is also increased. Of course, the following relationship exists when the occurred failure in Pull Off test is of cohesion failure type [38].

\subsection{The relationship between cohesion free energy and Pull Off test}

As mentioned before, different mechanisms play a role in moisture damage process. It is noteworthy that some of the parameters such as mastic cohesion strength affect

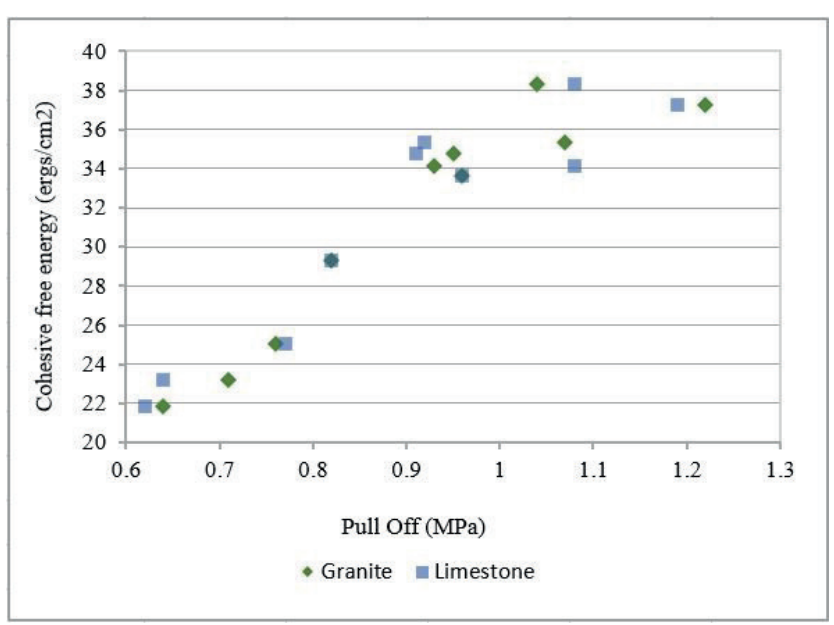

Fig. 12 Pull Off and cohesion free energy 
several mechanisms simultaneously indicating the existence of relationship between these mechanisms. For example, the thickness of asphalt binder film on the aggregates (mastic cohesion has a main role in its determination) can affect the amount of bearable force and failure type (cohesion or adhesive) and therefore, the mechanisms related to cohesion and adhesion. In this regard, the high thickness of asphalt binder film in asphalt mixtures causes an increase in the possibility of cohesion failure and fracture in mastic. Therefore, improving mastic properties can control failure type and affect positively cohesion failure. However, it is observed that, in previous research the total free energy of the binder is used twice as much to investigate cohesion free energy of mastic, and mastic properties are not considered in calculations $[15,16]$. Accordingly, the current research aims at exactly investigating the effects of filler on cohesion properties of mastic. In addition, attempts have been made to statistically investigate the relationship between cohesion free energy of binder in two states a) considering the effect of filler, and b) without considering the effect of filler using Pull Off test results. Results of the correlation between cohesion free energy and results of Pull Off test are presented in Table 3; in the first group (model 1) 4 base specimens and in the second group (model 2) 16 specimens contain different fillers. This investigation shows that the adjusted correlation coefficient between cohesion free energy and Pull Off test results has increased from 0.68 in 4 base compounds (without filler) to 0.92 in 16 compounds with filler. This significant difference in the adjusted correlation coefficient shows that using filler in determining cohesion free energy of binder has a better relation with Pull Off test. Accordingly, it is suggested to use SFE of mastic components instead of SFE of binder components in calculating parameters of cohesion free energy, aggregate-binder adhesive free energy, and debonding energy.

\section{Conclusions}

Considering the important role of filler in different mechanisms of moisture damage in asphalt mixtures, in the current research attempts were made to investigate the effect

Table 3 Correlation between cohesion free energy and Pull Off test in two groups

\begin{tabular}{lcccc}
\hline Model & $\mathrm{R}$ & R square & $\begin{array}{c}\text { Adjusted R } \\
\text { square }\end{array}$ & $\begin{array}{c}\text { Std. error of } \\
\text { the estimate }\end{array}$ \\
\hline 1 & 0.889 & 0.790 & 0.685 & 0.63462 \\
2 & 0.960 & 0.922 & 0.917 & 1.70206 \\
\hline
\end{tabular}

of filler type on moisture sensitivity of various asphalt mixtures. In addition, by comparing the relationship between Pull Off test results and those of SFE method attempts were made to investigate the effect of filler on both tests. Then considering that filler and binder in asphalt mixture are responsible for aggregates adhesion and cohesion in an integrated way, it was tried to statistically analyze the work of cohesion of asphalt binders with and without filler using results of Pull Off test.

The most important results obtained in line with the current research goal include:

- Generally, the use of hydrated lime and calcium carbonate fillers has caused an increase in TSR in the modified Lottman test (except in mixtures containing granite aggregate together with asphalt binder 60-70). In this case, hydrated lime filler is the most effective one. However, mixtures containing Portland cement show a different behavior, and this filler has shown a suitable resistance to moisture only in mixtures containing limestone and asphalt binder $85-100$ by $18 \%$ increase in TSR. Of course, in this group (limestone and asphalt binder 85-100), hydrated lime and calcium carbonate fillers have the maximum increase compared to base state by $33 \%$ and $30 \%$ increase, respectively. In addition, it is observed that compounds composed of limestone aggregate with both types of binder have almost the same behavior in hydrated lime and calcium carbonate fillers, and the numerical value of TSR in both types of binder is $96 \%$ and $94 \%$, respectively.

- The use of various fillers has caused a reduction in cohesion strength and as the result of this reduction, in contrast to the previous research, the failure occurred in Pull Off test is cohesion type in the particular testing conditions.

- The cohesion free energy in AC 60-70 samples is significantly higher compared to AC 85-100. It appears that viscosity is effective in increasing Pull Off values of asphalt binders.

- Investigating Pull Off tensile strength, it is observed that stone powder and Portland cement fillers have a less effect on cohesion strength reduction, but calcium carbonate and hydrated lime show the maximum effect and the minimum resistance against tensile force. In addition, hydrated lime filler in asphalt binder $60-70$ by $48 \%$ reduction and calcium carbonate filler in asphalt binder $85-100$ by $29 \%$ reduction have the minimum cohesion strength. 
- Thermodynamic investigation show that the reduction rate of cohesion free energy by adding filler to asphalt binder $60-70$ is more than asphalt binder $85-100$. For asphalt binder $60-70$, stone powder filler by $3 \%$ increase to the base state has the maximum amount of cohesion, and hydrated lime filler by $42 \%$ reduction has the minimum amount of cohesion. In specimens made by asphalt binder $85-100$, Portland cement filler and calcium carbonate have the maximum and minimum amount of cohesion free energy amongst mastics by $1.5 \%$ and $28 \%$ reduction to the base state, respectively. The results of this study coincide with the study by Caro et al. [39]. The results of their study show that the biomaterials contain several hydrophobic and hydrophilic functional groups that modified the chemical properties of the asphalt binder.

- Increase in the total free energy cause to increasing in the cohesion free energy and decreasing in the

\section{References}

[1] Arabani, M., Tahami, S., Taghipoor, M. "Laboratory investigation of hot mix asphalt containing waste materials", Road Materials and Pavement Design, 18(3), pp. 713-729, 2017.

https://doi.org/10.1080/14680629.2016.1189349

[2] Arabani, M., Tahami, S. "Assessment of mechanical properties of rice husk ash modified asphalt mixture", Construction and Building Materials, 149, pp. 350-358, 2017.

https://doi.org/10.1016/j.conbuildmat.2017.05.127

[3] Caro, S., Masad, E., Bhasin, A., Little, D. N. "Moisture susceptibility of asphalt mixtures, Part 2: characterisation and modelling", International Journal of Pavement Engineering, 9(2), pp. 99-114, 2008.

https://doi.org/10.1080/10298430701792144

[4] Caro Spinel, S. "A coupled micromechanical model of moisture-induced damage in asphalt mixtures:formulation and applications", PhD Dissertation, Texas A\&M University, 2009.

[5] Mirsayar, M. M., Huang, K., Zollinger, D. G. "New Approach to Determining Concrete Slab Lift-Off by Use of Interfacial Fracture Mechanics Concepts", Transportation Research Record: Journal of the Transportation Research Board, 2590(1), pp. 10-17, 2016.

https://doi.org/10.3141/2590-02

[6] Moghadas Nejad, F., Arabani, M., Hamedi, G., Azarhoosh, A. R. "Influence of using polymeric aggregate treatment on moisture damage in hot mix asphalt", Construction and Building Materials, 47, pp. 1523-1527, 2013.

https://doi.org/10.1016/j.conbuildmat.2013.06.060

[7] Little, D. N., Allen, D. H., Bhasin, A. "Chemical and Mechanical Processes of Moisture Damage in Hot-Mix Asphalt Pavements", In: Modeling and Design of Flexible Pavements and Materials, Springer, Cham, Switzerland, 2003, pp. 123-186.

https://doi.org/10.1007/978-3-319-58443-0_4 wettability of aggregates by asphalt binder. For this reason, increasing total free energy of asphalt binder cannot be a sufficient reason to improve moisture sensitivity of asphalt mixture.

- The adjusted coefficient of correlation between cohesion free energy and Pull Off test results has increased from 0.68 in 4 base compounds (without filler) to 0.92 in 16 compounds with filler. Therefore, using filler in cohesion free energy calculations has increased the accuracy in predicting the results of moisture sensitivity using SFE methods.

- In this study, two types of asphalt binders, two types of aggregates and four special filler types have been investigated. Also, the main focus was on the cohesion failure. Accordingly, in future studies, other combinations of asphalt mixtures with other tests and under conditions of adhesion failure can be investigated.

[8] Kringos, N., Scarpas, T., Kasbergen, C., Selvadurai, P. "Modelling of combined physical-mechanical moisture-induced damage in asphaltic mixes, Part 1: governing processes and formulations", International Journal of Pavement Engineering, 9(2), pp. 115-128, 2008. https://doi.org/10.1080/10298430701792185

[9] Arabani, M., Tahami, S. A., Hamedi, G. H. "Performance evaluation of dry process crumb rubber-modified asphalt mixtures with nanomaterial", Road Materials and Pavement Design, 19(5), pp. 1241-1258, 2018.

https://doi.org/10.1080/14680629.2017.1302356

[10] St Martin, J., Cooley, L. A., Hainin, H. R. "Production and construction issues for moisture sensitivity of hot-mix asphalt pavements", In: Moisture Sensitivity of Asphalt Pavements - A National Seminar, San Diego, CA, USA, 2003, pp. 209-222.

[11] Faramarzi, M., Golestani, B., Lee, K. W. "Improving moisture sensitivity and mechanical properties of sulfur extended asphalt mixture by nano-antistripping agent", Construction and Building Materials, 133, pp. 534-542, 2017. https://doi.org/10.1016/j.conbuildmat.2016.12.038

[12] Mohd. Jakarni, F. "Adhesion of asphalt", PhD Thesis, University of Nottingham, 2012. [online] Available at: http://eprints.nottingham. ac.uk/12646/1/Adhesion_of_Asphalt_Mixtures.pdf. [Accessed: 20 July 2012]

[13] Azarhoosh, A., Moghaddas Nejad, F., Khodaii, A. "Evaluation of the effect of nano-TiO2 on the adhesion between aggregate and asphalt binder in hot mix asphalt", European Journal of Environmental and Civil Engineering, 22(8), pp. 946-961, 2016. https://doi.org/10.1080/19648189.2016.1229227

[14] Kanitpong, K., Bahia, H. U. "Role of adhesion and thin film tackiness of asphalt binders in moisture damage of HMA", Association of Asphalt Paving Technologists - Proceedings of the Technical Sessions, 72, pp. 502-528, 2003. 
[15] Tan, Y., Guo, M. "Using surface free energy method to study the cohesion and adhesion of asphalt mastic", Construction and Building Materials, 47, pp. 254-260, 2013.

https://doi.org/10.1016/j.conbuildmat.2013.05.067

[16] Alvarez, A. E., Ovalles, E., Caro, S. "Assessment of the effect of mineral filler on asphalt-aggregate interfaces based on thermodynamic properties", Construction and Building Materials, 28(1), pp. 599-606, 2012. https://doi.org/10.1016/j.conbuildmat.2011.08.089

[17] Faheem, A. F., Bahia, H. U. "Modelling of Asphalt Mastic in Terms of Filler-Bitumen Interaction", Road Materials and Pavement Design, pp. 281-303, 2011. https://doi.org/10.1080/14680629.2010.9690335

[18] Shashidhar, N., Romero, P. "Factors Affecting the Stiffening Potential of Mineral Fillers", Transportation Research Record: Journal of the Transportation Research Board, 1638(1), pp. 94-100, 1998. https://doi.org/10.3141/1638-11

[19] Lv, D., Zheng, C., Qin, Y., Bi, H., Li, K., Huang, J. "Analysing the effects of the mesoscopic characteristics of mineral powder fillers on the cohesive strength of asphalt mortars at low temperatures", Construction and Building Materials, 65, pp. 330-337, 2014. https://doi.org/10.1016/j.conbuildmat.2014.04.123

[20] Xie, J., Wu, S., Pang, L., Lin, J., Zhu, Z. "Influence of surface treated fly ash with coupling agent on asphalt mixture moisture damage", Construction and Building Materials, 30, pp. 340-346, 2012. https://doi.org/10.1016/j.conbuildmat.2011.11.022

[21] Hamedi, G. H., Moghadas Nejad, F. "Use of aggregate nanocoating to decrease moisture damage of hot mix asphalt", Road Materials and Pavement Design, 17(1), pp. 32-51, 2015. https://doi.org/10.1080/14680629.2015.1056215

[22] Bhasin, A., Little, D. N., Vasconcelos, K. L., Masad. E. "Surface Free Energy to Identify Moisture Sensitivity of Materials for Asphalt Mixes", Transportation Research Record: Journal of the Transportation Research Board, 2001(1), pp. 37-45, 2007. https://doi.org/10.3141/2001-05

[23] Hamedi, G. H., Moghadas Nejad, F., Oveisi, K. "Estimating the moisture damage of asphalt mixture modified with nano zinc oxide", Materials and Structures, 49(4), pp. 1165-1174, 2016. https://doi.org/10.1617/s11527-015-0566-x

[24] Bhasin, A., Masad, E., Little, D., Lytton, R. "Limits on Adhesive Bond Energy for Improved Resistance of Hot-Mix Asphalt to Moisture Damage", Transportation Research Record: Journal of the Transportation Research Board, 1970(1), pp. 2-13, 2006. https://doi.org/10.1177/0361198106197000101

[25] Packham, D. E. "Handbook of adhesion", John Wiley \& Sons, Chichester, West Sussex, UK, 2005. https://doi.org/10.1002/0470014229

[26] Mercado, E. "Influence of Fundamental Material Properties and Air Void Structure on Moisture Damage of Asphalt Mixes", PhD Dissertation, Texas A\&M University, 2007.

[27] Miller, C. "Adhesion and the surface energy components of natural minerals and aggregates", Master's Thesis, Texas A \& M University, 2011.
[28] ASTM D3515-01 "Standard Specification for Hot-Mixed, HotLaid Bituminous Paving Mixtures", ASTM International, West Conshohocken, PA, USA, 2001. https://doi.org/10.1520/D3515-01

[29] Copeland, A. R., Youtcheff, J., Shenoy, A. "Moisture Sensitivity of Modified Asphalt Binders: Factors Influencing Bond Strength", Transportation Research Record: Journal of the Transportation Research Board, 1998(1), pp. 18-28, 2007. https://doi.org/10.3141/1998-03

[30] Kanitpong, K., Bahia, H. "Relating Adhesion and Cohesion of Asphalts to the Effect of Moisture on Laboratory Performance of Asphalt Mixtures", Transportation Research Record: Journal of the Transportation Research Board, 1901(1), pp. 33-43, 2005. https://doi.org/10.1177/0361198105190100105

[31] Chaturabong, P., Bahia, H. U. "The evaluation of relative effect of moisture in Hamburg wheel tracking test", Construction and Building Materials, 153, pp. 337-345, 2017. https://doi.org/10.1016/j.conbuildmat.2017.07.133

[32] Solaimanian, M., Harvey, J., Tahmoressi, M., Tandon, V. "Test methods to predict moisture sensitivity of hot-mix asphalt pavements", In: Moisture Sensitivity of Asphalt Pavements - A National Seminar, San Diego, CA, USA, 2003, pp. 77-110.

[33] Hicks, R. G., Santucci, L., Aschenbrener, T. "Introduction and seminar objectives", In: Moisture Sensitivity of Asphalt Pavements A National Seminar, San Diego, CA, USA, 2003, pp. 3-20.

[34] Bhasin, A. "Development of methods to quantify bitumen-aggregate adhesion and loss of adhesion due to water", $\mathrm{PhD}$ Dissertation, Texas A\&M University, 2006.

[35] Hefer, A. W., Bhasin, A., Little, D. N. "Bitumen Surface Energy Characterization Using a Contact Angle Approach", Journals of Materials in Civil Engineering, 18(6), pp. 759-767, 2006. https://oi.org/10.1061/(ASCE)0899-1561(2006)18:6(759)

[36] Habal, A., Singh, D. "Comparison of Wilhelmy plate and Sessile drop methods to rank moisture damage susceptibility of asphalt Aggregates combinations", Construction and Building Materials, 113, pp. 351-358, 2016.

https://doi.org/10.1016/j.conbuildmat.2016.03.060

[37] Zhang, X. J., Feng, H. X., Li, X. M., Ren, X. Y., Lv, Z. F., Li, B. "Effect of Material Composition on Cohesion Characteristics of Styrene-Butadiene-Styrene-Modified Asphalt Using Surface Free Energy", Advances in Materials Science and Engineering, 2017, Article ID: 9832406, 2017. https://doi.org/10.1155/2017/9832406

[38] Moraes, R., Velasquez, R., Bahia, H. "Using bond strength and surface energy to estimate moisture resistance of asphalt-aggregate systems", Construction and Building Materials, 130, pp. 156-170, 2017.

https://oi.org/10.1016/j.conbuildmat.2016.10.043

[39] Caro, S., Vega, N., Husserl, J., Alvarez, A. E. "Studying the impact of biomodifiers produced from agroindustrial wastes on asphalt binders", Construction and Building Materials, 126, pp. 369-380, 2016.

https://doi.org/10.1016/j.conbuildmat.2016.09.043 